\title{
BYD Financial Risk Early Warning Research
}

\author{
Lu Zhai ${ }^{1, a,{ }^{*}}$, Yuze $\mathrm{Li}^{2, \mathrm{~b}}$ \\ ${ }^{1}$ Beijing Jiaotong University, Beijing, China \\ ${ }^{2}$ Beijing No. 8 Middle School, Beijing, China \\ a17120674@bjtu.edu.cn, ${ }^{b} 15522876717 @ 163 . c o m$ \\ ${ }^{*}$ Corresponding authori
}

Keywords: new energy vehicles; BYD; financial risks; financial warning

\begin{abstract}
Under the macro background of severe deterioration of air quality, rapid development of science and technology and support of national policies, new energy vehicles have great potential for development, but the characteristics of large investment and unstable income in the early stage have made new energy automobile enterprises face high financial risks. This paper uses case analysis method, BYD Co., Ltd. as the research object, and builds a financial early warning model based on binomial logistic regression to warn BYD financial risks. It aims to provide effective advice for BYD and the new energy auto industry to control financial risks. The paper concludes that the BYD energy vehicle business has a promising future, but also faces serious financial risks. BYD should take timely measures to reduce financial risks and improve financial conditions.
\end{abstract}

\section{Introduction}

In recent years, China has been plagued by haze weather. In order to promote the transformation of the automobile industry and improve the air situation, the State Council issued a notice on the “China Energy Conservation and New Energy Vehicle Industry Development Plan”, vigorously promoted green GDP and implemented a number of preferential policies to support it. The new energy vehicle industry is therefore expected to see explosive growth in the next few years.

As a listed national independent brand, BYD seized the opportunity of new energization of automobiles, took advantage of the power battery, adhered to independent research, and occupied the leading position of the new energy automobile industry, but problems such as high product cost, technical difficulties, imperfect supporting facilities restrict the development of the enterprise. Large demand for R\&D funds and the unstable income also make BYD bear greater financial risks. If the financial risks are too high, the company will suffer losses or even bankruptcy. Faced with fierce competition from domestic and foreign auto giants, how BYD grasps the strategic transition period, controls the financial risks to grow steadily, and raises the national brand awareness, which deserves in-depth study.

Based on the promising development trend of the automotive industry in recent years, this paper selects BYD as the research object, trying to analyze the potential financial risks of BYD, and builds a financial risk early warning model to make the healthy development of the enterprise and provide reference for the new energy automobile industry.

\section{Literature Review}

Edward Altman (1968) of Columbia University first proposed a multivariate linear discriminant method. He defined the bankruptcy state as the financial crisis of the enterprise and created the famous multivariate financial early warning model, the $\mathrm{Z}$ model. And concluded that the smaller the $\mathrm{Z}$ value, the greater the likelihood of a financial crisis. Shouhua Zhou, Jihua Yang and Ping Wang (2000) took the cash flow into consideration, improved the Z-Score model, introduced indicators for measuring the solvency of enterprises, and proposed a more comprehensive F-Score model to make up for defects in the Z-score model. Martin (1977) firstly used the method of logistic regression analysis to construct a conditional probability model and conducted an early-warning study on the 
financial risk of the enterprise. It was found that in the case of nonlinearity, the risk discrimination of the Logistic model is higher than that of the Z-Score model. Qiuping Cai (2006) used two logistic regression analysis to establish a financial early warning model for listed companies in Beijing, Shanghai and Jiangsu. The research shows that the model has a high early warning rate. Because the method is convenient to operate, and can meet the prediction of multiple indicator variables. Scholar Mokhatab Rafioi (2011) mainly uses artificial neural networks and multiple regression methods to conduct early-warning analysis of potential financial risks of enterprises. Finally, he found that artificial neural networks show better prediction accuracy than other models and have better predictions.

Through research on domestic and foreign research, the current literature rarely involves the automobile industry. Most of the research is aimed at automobile enterprises and development strategies. Therefore, the author is based on China's listed automobile manufacturing industry, with the national brand BYD as a case, uses the single-index T-test method to screen financial indicators and binomial logistic regression method to construct the financial early warning model, determining the financial risk degree of BYD Company and proposing risk control recommendations.

\section{Construction Of Early Warning Model}

\subsection{Sample and indicator selection}

Based on the research object of this paper, BYD Company belongs to the automobile manufacturing industry. In order to make the early warning model more targeted, the selected research samples belong to the automobile manufacturing industry, and most of them are vehicle manufacturing enterprises or auto parts manufacturing enterprises. In the end, this paper selected six automobile companies that were specially treated (ST) and 34 automobile companies that were not specially treated (not ST) in 2014-2016. All data is from the CSMAR database.

Based on previous research data and considering the characteristics of the automobile manufacturing industry, this paper selects the current ratio, the operating net profit rate, the inventory turnover rate, and the five aspects of solvency, profitability, operational capability, development capability and cash flow status, operating income growth rate and cash flow short-term debt ratio as preliminary research indicators for 16 financial indicators, and will be further screened in the subsequent regression analysis.

\subsection{Logistic regression analysis}

This paper needs to conduct a second test on the preliminary sample $\mathrm{T}$ test of the 16 selected financial indicators to ensure that the selected indicators are significantly different between the ST and non-ST companies. The data is collected by SPSS 17.0. The software performs calculations, and the $\mathrm{T}$ test results are as follows 
Table 1. Financial indicator T test results

\begin{tabular}{|c|c|c|c|}
\hline Indicator code & Indicator name & $\mathrm{T}$ value & $\mathrm{P}$ value \\
\hline $\mathrm{X} 1$ & Current ratio & 3.873 & $0.000 * * *$ \\
\hline $\mathrm{X} 2$ & Quick ratio & 3.834 & $0.000 * * *$ \\
\hline X3 & Assets and liabilities & -3.029 & $0.003 * * *$ \\
\hline $\mathrm{X} 4$ & Operating net profit margin & 3.842 & $0.001 * * *$ \\
\hline $\mathrm{X} 5$ & Roe & 2.443 & $0.026 * *$ \\
\hline X6 & Total net profit margin & 5.257 & $0.000 * * *$ \\
\hline $\mathrm{X} 7$ & Inventory turnover & 1.582 & 0.116 \\
\hline $\mathrm{X} 8$ & $\begin{array}{c}\text { Accounts receivable } \\
\text { turnover }\end{array}$ & 0.426 & 0.671 \\
\hline X9 & Total asset turnover & 1.601 & 0.112 \\
\hline $\mathrm{X} 10$ & $\begin{array}{l}\text { Operating income growth } \\
\text { rate }\end{array}$ & 0.014 & 0.989 \\
\hline $\mathrm{X} 11$ & Net profit growth rate & 0.202 & 0.840 \\
\hline $\mathrm{X} 12$ & Total asset growth rate & 4.094 & $0.000^{* * *}$ \\
\hline $\mathrm{X} 13$ & $\begin{array}{l}\text { Capital preservation and } \\
\text { appreciation rate }\end{array}$ & 1.099 & 0.286 \\
\hline $\mathrm{X} 14$ & $\begin{array}{l}\text { Cash flow short-term debt } \\
\text { ratio }\end{array}$ & 4.212 & $0.000 * * *$ \\
\hline $\mathrm{X} 15$ & Cash flow debt ratio & 4.027 & $0.000 * * *$ \\
\hline $\mathrm{X} 16$ & Operating income cash ratio & 2.219 & $0.028 * *$ \\
\hline
\end{tabular}

Note: ${ }^{*} \mathrm{p}<0.1 * * \mathrm{p}<0.05 * * * \mathrm{p}<0.01$

In order to make the independent variables of the logistic regression model more accurate, this paper uses the $1 \%$ significance level as a standard to screen the preliminary financial indicators. According to the results, among the 16 financial indicators initially selected, only X1 (current ratio), X2 (quick ratio), X3 (asset ratio), X4 (operating net rate), X6 (total net asset rate), X12 (total asset growth rate), X14 (cash flow short-term debt ratio) and X15 (cash flow total debt ratio) can be selected as indicators for the financial early warning model of this study, namely the ST company and the non-ST company in these eight indicators There are significant differences.

The Logistic early warning model is built based on these eight indicators (X1, X2, X3, X4, X6, $\mathrm{X} 12, \mathrm{X} 14, \mathrm{X} 15)$. First, the explanatory variable, that is, whether the financial status of the listed company of the automobile has a crisis (here, whether it is ST or not) takes values of 0 and 1 , where 0 represents the company whose financial abnormality is ST, and 1 is financial condition is running normally and is not listed by ST's listed company. Then, by introducing the data of the first three years of ST selected by the above-mentioned financial early warning indicators (X1, X2, X3, X4, X6, X12, X14, X15), based on the binomial logistic regression model, using SPSS 17.0 statistical software. The calculation yields the following regression results. 
Table 2. Logistic Regression Results

\begin{tabular}{ccccccc}
\hline step 1 & B & S.E, & Wals & df & Sig. & Exp (B) \\
\hline X1 & 2.156 & 4.719 & .209 & 1 & .648 & .116 \\
\hline X2 & -.951 & 4.742 & .040 & 1 & .841 & 2.589 \\
\hline X3 & .151 & 3.747 & .002 & 1 & .968 & .860 \\
\hline X4 & 22.262 & 29.144 & .583 & 1 & .445 & .000 \\
\hline X6 & 16.871 & 43.544 & .150 & 1 & .698 & .000 \\
\hline X12 & 4.025 & 4.242 & .900 & 1 & .343 & .018 \\
\hline X14 & -6.752 & 21.869 & .095 & 1 & .758 & 855.890 \\
\hline X15 & 6.214 & 25.224 & .061 & 1 & .805 & .002 \\
\hline constant & -.800 & 3.444 & .054 & 1 & .816 & 2.224 \\
\hline
\end{tabular}

Therefore, according to the results of binomial logistic regression, the financial early warning model of the listed company in this study for the first three years of ST can be obtained as follows:

$$
P=\frac{1}{1+e^{0.8-2.156 X_{1}+0.951 X_{2}-0.151 X_{3}-22.262 X_{4}-16.871 X_{6}-4.025 X_{12}+6.752 X_{14}-6.214 X_{15}}}
$$

For the early warning model, take 0.5 as the demarcation point, and the value of $\mathrm{P}$ ranges from 0 to 1 . Therefore, when $0.5<\mathrm{P} \leq 1$, it can be judged that the company is $\mathrm{ST}$. When $0 \leq \mathrm{P}<0.5$, it can be judged as not being ST.

\subsection{Model comprehensive test}

Table 3. Model Summary

\begin{tabular}{cccc}
\hline Step size $(\mathrm{T})$ & -2Log likelihood & Cox \& Snell R2 & Nagelkerke R2 \\
\hline 1 & $49.965 a$ & .351 & .608 \\
\hline a. The estimate ends at iteration number 8, because the parameter estimate change is less than .001
\end{tabular}

Table 4. Omnibus Test Of Model Coefficients

\begin{tabular}{cccc}
\hline & Chi-square & Degree of freedom & Significant \\
\hline Step size $(\mathrm{T})$ & 50.496 & 9 & .000 \\
\hline Block & 50.496 & 9 & .000 \\
\hline Model & 50.496 & 9 & .000
\end{tabular}

The results show a -2 log likelihood value and two pseudo-determination coefficients. The two pseudo-determination coefficients reflect that the independent variable explains the proportion of the total variation of the dependent variable's variance to the dependent variable, indicating that the six independent variables account for $61 \%$ of the dependent variable, ie, whether the enterprise has financial risk (whether it is ST or not). From the global test results of the model, it can be seen that the three results sig values of the likelihood ratio test are less than 0.05 , indicating that the model is statistically significant.

\subsection{BYD financial risk early warning analysis}

Table 5. BYD Model Operation Results For 2014-2016

\begin{tabular}{cccccccccc}
\hline & X1 & X2 & X3 & X4 & X6 & X12 & X14 & X15 & P \\
\hline 2016 & 0.83 & 0.59 & 0.69 & 0.04 & 0.03 & 0.23 & 0.06 & 0.05 & 0.93 \\
\hline 2015 & 0.77 & 0.58 & 0.69 & 0.01 & 0.01 & 0.21 & 0.00 & 0.00 & 0.84 \\
\hline 2014 & 0.68 & 0.48 & 0.67 & 0.01 & 0.01 & 0.11 & 0.06 & 0.05 & 0.74 \\
\hline
\end{tabular}

The value of the eight financial indicators of BYD in the past three years was substituted into the above financial early warning model. It was found that BYD's three-year P value was greater than the warning value of 0.5 , indicating that BYD had a special risk, the company had a financial crisis, but the $\mathrm{P}$ value Increasing year by year indicates that BYD's financial risks are increasing year by year, and it is urgent to take measures to reduce the company's financial risks. 


\section{Summary And Suggestions}

New energy vehicles are expected to usher in explosive growth. As a national independent brand that insists on independent research and development, BYD has achieved first-mover advantage in the field of new energy vehicles, and its development prospects are optimistic. However, through the financial risk early warning research on BYD, it is found that BYD has financial problems such as excessive proportion of fixed assets, unreasonable long-term and short-term debt structure, rapid growth of accounts receivable and rising costs, facing serious financial risks. The following suggestions are made for this.

Reasonably formulate the scale of fundraising and optimize the capital structure of enterprises. BYD should comprehensively consider the macroeconomic environment, national policy trends, the scale of its own business and other factors, fully do a good job in financial budgeting, and formulate a scientific fundraising scale suitable for the future development needs of enterprises to prevent excessive debt. Short-term borrowings are the most important source of financing for enterprises, and the huge interest charges incurred cause enterprises to face severe debt repayment pressure. Enterprises should optimize the capital structure, balance the ratio between long-term and short-term loans, and conduct diversified financing, such as through equity financing, bond financing and the introduction of corporate investors, etc., reducing the risk of BYD financing.

Strengthen the management of accounts receivable. In recent years, BYD's accounts receivable have risen rapidly, the turnover rate has continued to fall, and hundreds of millions of bad debt losses have resulted in a decline in the quality of revenue, resulting in certain capital recovery risks. BYD should balance the profitability and risk, and formulate reasonable credit policies and credit standards. They should conduct credit investigations on customers in advance, such as establishing a customer credit system, using the ratio analysis method to quantitatively investigate the financial status of customers, etc. The account policy is divided into levels according to the aging analysis method, and is classified and processed; the appropriate repayment preferential policy is adopted to accelerate the collection of accounts, shorten the payback period, reduce the opportunity cost and bad debt loss, and also control the collection fee.

Control expansion speed and reduce costs. When BYD entered the automotive industry, it achieved low-cost advantages through vertical integration strategy and achieved good results. Since then, BYD has borrowed heavily for rapid enterprise expansion, resulting in high management costs and financial expenses, which has caused BYD to lose its low-cost advantage. Therefore, BYD should control the expansion speed, invest funds in key areas, and regain the low cost advantage.

Focus on the development of new energy vehicles and divest non-main business.

BYD's current main business includes automotive, mobile phone OEM, rechargeable battery and photovoltaic. From the 2014-2015 BYD operating income structure, new energy vehicles have become BYD's new profit growth point and have broad development prospects. In contrast, the traditional fuel vehicle market is close to saturation, and it loses its low-cost advantage, and its sales volume has fallen sharply. The photovoltaic industry's development environment has deteriorated and its business growth rate is extremely low. BYD should stop some traditional models with low profit margins, abandon the low-end market of mobile phone business, reduce investment in photovoltaic business, concentrate on developing new energy automobile industry, increase investment in research and development, and introduce differentiated models to increase profit margin.

In general, BYD's future can be said to be both risks and opportunities. It is hoped that during the critical period of automobile industry transformation, BYD can make full use of the favorable policies provided by the state and take corresponding measures to reduce financial risks and create high-quality national brands.

\section{References}

[1] Beaver W. H. Financial Ratios as Predictors of Failure [J]. Journal of Accounting Research (Supplement),1996. 
[2] Paul J Fitzpatrick. A Comparison of Ratios of successful Industrial Enterprises With Those Failed Firms [J]. Certified Public Accountant,1932, 10:592 611

[3] Ning M. Risk Matrix of Accounting Risk Measurement and Implication [J].2011.

[4] E.T.Altman. Financial Ratios Discriminant Analysis and the Prediction of Corporate Failure.Journal of Finance.1968,23(4): 590-609.

[5] M.E.Zmijewski. Method of Logistical Issues Related to The Estimation of Financial Distress Prediction Models. Journal of Accounting Research, 2004,(10). 